Jäger - Neue Unternehmen und alternative Betriebe 
Wieland Jäger

\section{Neue Unternehmen}

und alternative Betriebe

Kulturelle Aspekte

betrieblichen Handelns 
Wieland Jäger, Prof. Dr. phil. habil., ist Hochschullehrer für Soziologie, insbesondere Arbeitssoziologie, an der FernUniversität Hagen.

Die Deutsche Bibliothek - CIP-Einheitsaufnahme

\section{Jäger, Wieland:}

Neue Unternehmen und alternative Betriebe : kulturelle

Aspekte betrieblichen Handelns / Wieland Jäger. - Wiesbaden :

Gabler, 1991

Der Gabler Verlag ist ein Unternehmen der Verlagsgruppe Bertelsmann International.

(C) Betriebswirtschaftlicher Verlag Dr. Th. Gabler GmbH, Wiesbaden 1991

Lektorat: Gudrun Knöll

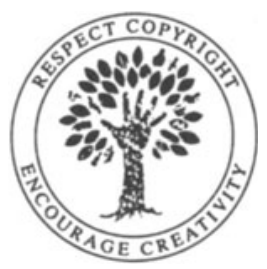

Das Werk einschließlich aller seiner Teile ist urheberrechtlich geschützt. Jede Verwertung außerhalb der engen Grenzen des Urheberrechtsgesetzes ist ohne Zustimmung des Verlags unzulässig und strafbar. Das gilt insbesondere für Vervielfältigungen, Übersetzungen, Mikroverfilmungen und die Einspeicherung und Verarbeitung in elektronischen Systemen.

Dieses Buch wurde auf säurefreiem und chlorarm gebleichtem Papier gedruckt. 


\section{Inhaltsverzeichnis}

Illustrationen und Schaubilder

$\begin{array}{ll}\text { Vorbemerkung } & 5\end{array}$

1 Die neue Sicht - Anstöße und Begründungen 6

2 Neue Kooperationsformen der Arbeit 17

2.1 Partnerschaft in der Wirtschaft -

$\begin{array}{ll}\text { Ansprüche und Empfehlungen an "Neue Unternehmen" } & 17\end{array}$

2.2 Das innovative Potential der Alternativbetriebe 30

3 Zur Kultur des betrieblichen Handelns -

$\begin{array}{ll}\text { Grundlegungen und erste Ergebnisse } & 34\end{array}$

3.1 Kultur und Wirtschaft, Markt und Gesellschaft 34

3.2 Unternehmens- und Organisationskultur - nur ein Modethema? 37

3.3 Selbstorganisierte Betriebe und der Kulturkontext 41

3.4 Verständigungskultur - Kommunikation und Information 47

Entscheidungsprozesse - Kristallisationspunkt
der Kultur betrieblichen Handelns

4 "Neue Unternehmen" - Betriebliche Realität und Probleme 74

4.1 Exkurs: Ota Šik - Humane Wirtschaftsdemokratie.

Ein dritter Weg 
5 "Neuer kooperativer Wirtschaftssektor", Selbstorganisation und dezentrale Produzentendemokratie Einige Trends, Tendenzen und Entwicklungen

5.1 Entscheidungsstrukturen zwischen

Selbstbestimmung und Verantwortung

5.2 Arbeitszeit in selbstverwalteten Betrieben

5.3 Transformation durch Ökonomisierung und Professionalisierung der Alternativbetriebe?

6 Blick über die Grenzen -

Zur Kultur des betrieblichen Handelns in Schweden und Norwegen

6.1 Das LOM Programm in Schweden

6.2 Das HABUT Programm in Norwegen

158

7 Vom "Objekt des Verfahrens" zum "Subjekt des Handelns"? -

Würdigung und Kritik in weiterführender Absicht 


\section{Illustrationen und Schaubilder}

Von der materiellen zur immateriellen Technik $\quad 18$

AGP-Empfehlungen zur immateriellen Mitarbeiterbeteiligung 19

Ganzheitliche Unternehmensführung $\quad 23$

"... wir verstehen uns als Mitarbeiter!" 25

$\begin{array}{ll}\text { Beispiel CNC-Maschine } & 27\end{array}$

Beispiel Bildschirmgerät $\quad 28$

$\begin{array}{ll}\text { Beispiel PPS-System } & 29\end{array}$

Mikroorganisatorische Gestaltungsinhalte $\quad 45$

Gestaltungstechniken im Rahmen der Selbstorganisation $\quad 46$

Entwicklung der Datenverarbeitung zum Informationswesen $\quad 50$

Gesamtaufbau des Informationswesens $\quad 51$

Grundsätzlicher Kommunikationsablauf bei konventioneller Ausrüstung $\quad 52$

Grundsätzlicher Kommunikationsablauf bei

vollintegrierter elektronischer Ausrüstung $\quad 53$

Grundsätzlicher Kommunikationsablauf bei gemischter Ausrüstung 54

Informationshierarchie und Kommunikationssteuerung 55

$\begin{array}{ll}\text { Genese der betrieblichen Sozialverfassung } & 65\end{array}$

Einflußfaktoren auf die betriebliche Sozialverfassung $\quad 66$

Die Trennung von Entscheidungsbefugnissen

in größeren Genossenschaften $\quad 70$

$\begin{array}{ll}\text { Weniger arbeiten oder mehr verdienen? } & 73\end{array}$

$\begin{array}{ll}\text { Wirtschaftsbeirat KMK } & 77\end{array}$

Information, Kommunikation, Training bei Drägerwerk $\quad 81$

Arbeitsschritte des Qualitätszirkels im Drägerwerk $\quad 82$

Kommunikation bei Taylorix $\quad 86$

Hewlett-Packard-Way - Unser Führungsstil $\quad 88$

$\begin{array}{lr}\text { PSI-Modellstruktur } & 90\end{array}$

Grundlagen der Selbstbestimmung bei PSI $\quad 91$

Wertorientierungen des PSI-Firmenmodells $\quad 93$

$\begin{array}{ll}\text { Vielfalt der Konflikte bei PSI } & 94\end{array}$

Allgemeine Grundsätze und Prinzipien bei randstad 96

Allgemeine Zielsetzung bei randstad $\quad 97$

$\begin{array}{lr}\text { Entscheidungsstruktur in der Mitarbeitergesellschaft } & 107\end{array}$

$\begin{array}{ll}\text { Schema der Projektarbeit } & 139\end{array}$

Modell des neuen Volvo-Werks in Uddevalla $\quad 174$ 